\title{
Field trials of enhanced weathering combined with cotton farming in Thessaly, Greece.
}

\author{
INGRID SMET ${ }^{1}$, ELEFTHERIOS EVANGELOU ${ }^{2}$, \\ CHRISTOS TSADILAS ${ }^{2}$, MATHILDE HAGENS ${ }^{3}$, JELLE \\ BIJMA $^{4}$, JENS HARTMANN ${ }^{5}$, RALF STEFFENS ${ }^{6}$ AND \\ DIRK PAESSLER ${ }^{6}$
}

${ }^{1}$ Fieldcode Greece M.I.K.E.

${ }^{2}$ Institute of Industrial and Forage Crops

${ }^{3}$ Wageningen University \& Research

${ }^{4}$ Alfred-Wegener-Institute, Helmholtz-Zentrum für Polar- und Meeresforschung

${ }^{5}$ Institute for Geology, Univ. Hamburg

${ }^{6}$ Carbon Drawdown Initiative Carbdown $\mathrm{GmbH}$

Presenting Author: ingrid.smet@fieldcode.com

Besides extensive reduction of greenhouse gas emissions, reaching the Paris Agreement climate targets requires a portfolio of carbon dioxide removal (CDR) techniques. Enhancing the natural process of chemical rock weathering is one such method. Applied to agricultural areas, enhanced weathering (EW) could remove significant amounts of atmospheric $\mathrm{CO}_{2}$ whilst also having beneficial effects on crop yield and soil quality [1].

The effectiveness of EW combined with agriculture will vary with climate, soil, crop and rock type, hence field trials are urgently needed to evaluate its carbon sequestration potential [2]. Under the umbrella of Project Carbdown multiple field trials, pot and lab experiments are carried out across Europe, testing locally relevant EW treatments in synchronized projects. We assess safety and effectiveness besides looking for practical ways to quickly scale up this method.

One of our projects in Greece combines EW with cotton, a widely cultivated crop with a relatively high water demand. Seven treatments with EU sourced (ultra) mafic rocks [3] are applied at a rate of $4 \mathrm{~kg} / \mathrm{m}^{2}$ on $4 \mathrm{~m}$ by $8 \mathrm{~m}$ plots each replicated four times. We also test the Greek rock dusts on larger areas (0.25ha) at a rate of 1.2 ton/ha to evaluate the CDR potential in accordance with current Ni legislation. Some treatments include biochar to assess its synergy with EW, and the entire field is managed according to local cotton farming practices. We will present details on the concept and practical set-up of this 2021 field trial, along with the first results.

For quantification of $\mathrm{CO}_{2}$ removal, we analyse soil water for DIC, $\mathrm{pH}$, alkalinity and $\mathrm{Mg}$ ions. In soil samples we additionally determine CEC, SOC and N, P, K, Ca, Ni, and Cr. In order to examine EW effects on the crop nutrition, plant tissue collected at blooming stage is examined for major elements. Soil temperature, moisture, $\mathrm{pH}$ and alkalinity are monitored throughout in situ with the aim to develop a robust method for simple CDR quantification on the field.

[1] Hartmann et al (2013), Reviews of Geophysics 51, 113149.

[2] Andrews \& Taylor (2019), Elements 15, 253-258.

[3] Kremer et al (2019), Minerals 9, 485. 